Sir,

\section{Topical timolol prevented migraine attacks}

Topical administration of timolol eye drops has systemic side effects. There have been 547 reports of adverse reactions and approximately half the reports concerned systemic reactions. ${ }^{1}$ Topical timolol maleate has also been noted to reduce the frequency and symptoms of ophthalmoplegic migraine in a 4-year-old girl. ${ }^{2}$ We report a case in which topical application of timolol drops had beneficial effect in a patient suffering from common migraine.

\section{Case report}

A 64-year-old lady suffered with common migraine. Her headaches occurred once a month with no premonitory features and lasted for 8-12 h. They usually started on the right side and became generalized. She had associated retro-orbital pain, photophobia, and nausea with occasional vomiting during her attacks. She had tried migraleve tablets, which were not very effective. Her mother was known to suffer from classical migraine. Subsequently, she was diagnosed as having bilateral ocular hypertension and was started on $0.5 \%$ timolol maleate topically to both eyes. She had no further attacks of migraine for the last 18 years.

\section{Comment}

Systemic beta-blockers such as propranolol, metoprolol, timolol, atenolol, and nadolol have been used as prophylactic agents for the prevention of migraine attacks. ${ }^{3}$ Systemic propranolol and timolol have been shown to have equal efficacy as prophylactic agents. ${ }^{4}$ The most likely mechanism by which beta-blockers act is through stabilization of the intrasynaptic serotonin-level in the serotonergic neurons of the brainstem. ${ }^{5}$ Betablockers without intrinsic sympathomimetic activity (ISA) appear to be more effective than those with ISA. 3,6 Systemic timolol is known to decrease migraine attacks in patients with common as well as classical migraine. ${ }^{6}$

Topical timolol maleate reaches concentrations in plasma of $0.5 \mathrm{ng} / \mathrm{ml}$ and $0.3 \mathrm{ng} / \mathrm{ml}$ within $4 \mathrm{~h}$ following the first and second dose, respectively. ${ }^{7}$ It bypasses the first pass metabolism to reach the systemic circulation. This concentration in plasma is associated with its systemic side effects. Among the serious ones are depression, anxiety, confusion, bradycardia, arrhythmias, and pulmonary airway obstruction. ${ }^{1}$ This possible beneficial systemic side effect has hardly been reported. A previous case reported a 4-year-old girl with ophthalmoplegic migraine treated with $0.25 \%$ timolol maleate twice daily to both eyes. She experienced a remarkable reduction in the frequency and symptoms of migraine. ${ }^{2}$ To our knowledge, this is the only other case report of the beneficial effects of topical timolol maleate. Topical or possibly sublingual administration may be an alternative mode of drug delivery in migraine patients.

\section{References}

1 Van Buskirk EM. Adverse reaction from timolol administration. Ophthalmology 1980; 87(5): 447-450.

2 Ishikawa H, Yoshihara M, Mizuki K, Kashima Y. A pediatric case of ophthalmoplegic migraine with recurrent oculomotor nerve palsy. Jpn J Ophthalmol 2000; 44(5): 576.

3 Massiou H, Bousser MG. Beta-blockers and migraine. Pathol Biol 1992; 40(4): 373-380.

4 Tfelt-Hansen P. Efficacy of beta-blockers in migraine. A critical review. Cephalagia 1986; 6(Suppl. 5): 15-24.

5 Pfaffenrath V, Pollman W, Kufner G, Drubba S. Migraine and beta-blocker. An overview. Fortschr Neurol-Psychiatrie 1985; 53(1): 13-21.

6 Anderson KE, Vine E. Beta-adrenoceptor blockers and calcium antagonists in the prophylaxis and treatment of migraine. Drugs 1990; 39(3): 355-373.

7 Shedden AH, Laurence J, Barrish A, Olah TV. Plasma timolol concentrations of timolol maleate: timolol gel-forming solution (TIMOPTIC-XE) once daily versus timolol maleate ophthalmic solution twice daily. Documenta Ophthalmol 2001; 103(1): 73-79.

J Bhagey and B James

Department of Ophthalmology

Stoke Mandeville Hospital

Aylesbury HP 219 AN, UK

Correspondence: B James

Tel: + $44(0) 1296315034$

Fax: + 44 (0)1296 315037

E-mail: bruce.james@smh.nhs.uk

Eye (2004) 18, 751. doi:10.1038/sj.eye.6701303

Published online 6 February 2004 